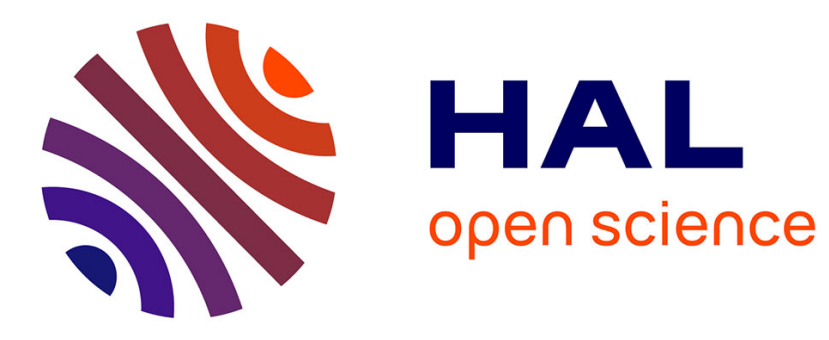

\title{
Self-Deployable Geometries for Space Applications
}

William Bettini, Jérôme Quirant, Julien Averseng, Bernard Maurin

\section{To cite this version:}

William Bettini, Jérôme Quirant, Julien Averseng, Bernard Maurin. Self-Deployable Geometries for Space Applications. Journal of Aerospace Engineering, 2019, 32 (1), pp.04018138. 10.1061/(ASCE)AS.1943-5525.0000967 . hal-01939408

\section{HAL Id: hal-01939408 \\ https://hal.science/hal-01939408}

Submitted on 29 Nov 2018

HAL is a multi-disciplinary open access archive for the deposit and dissemination of scientific research documents, whether they are published or not. The documents may come from teaching and research institutions in France or abroad, or from public or private research centers.
L'archive ouverte pluridisciplinaire HAL, est destinée au dépôt et à la diffusion de documents scientifiques de niveau recherche, publiés ou non, émanant des établissements d'enseignement et de recherche français ou étrangers, des laboratoires publics ou privés. 


\title{
SELF DEPLOYABLE GEOMETRIES FOR SPACE APPLICATIONS
}

William Bettini ${ }^{(1)}$, Jérôme Quirant ${ }^{(2)}$, Julien Averseng ${ }^{(3)}$, Bernard Maurin ${ }^{(4)}$

\section{Affiliations:}

Bettini W., Ph'D Student, LMGC, Univ Montpellier, CNRS, CC048, 163 rue Auguste Broussonnet, 34090 Montpellier, France, william.bettini@umontpellier.fr, (corresponding author)

Quirant J., Associate Pr., LMGC, Univ Montpellier, CNRS, CC048, 163 rue Auguste Broussonnet, 34090 Montpellier, France, jerome.quirant@ umontpellier.fr

Averseng J., Associate Pr., LMGC, Univ Montpellier, CNRS, CC048, 163 rue Auguste Broussonnet, 34090 Montpellier, France, julien.averseng@umontpellier.fr

Maurin B., Pr., LMGC, Univ Montpellier, CC048, 163 rue Auguste Broussonnet, 34090 Montpellier, CNRS, Montpellier, France, bernard.maurin@umontpellier.fr

\begin{abstract}
:
Variable-geometry structures are useful in aerospace applications since they are adaptable, from a compact configuration (launch phase) to a spread geometry (operational phase). They may also benefit from the use of flexible joints, which store elastic energy for automatic deployment. Following the development of a self-deploying antenna frame structure with scissors, we propose in this article the geometrical configuration of a new kind of structure, simpler and lighter, minimizing mechanical joints between elements. This topology can form a circular plane or a three-dimensional structure when partially opened. The applications concern auto-tensioning structures such as meshed space antenna, deorbiting sails and also solar panels support structures.
\end{abstract}

\section{KEYWORDS}

Self-deployable structure, static equilibrium, numerical simulation, analytical model, sails, 
rigid structure.

\section{Introduction}

Variable-geometry structures are widely used in aerospace applications. Indeed, they go through different configurations, from a compact geometry during the launch phase to a large one in operational phase. There exist solutions with several modules that allow to form linear truss (Chu et al. 2014) in order to deploy Large Deployable Reflector (LDR). Many systems have also been developed like inflatable beams or tape booms for solar sails (Jianzheng et al. 2014), conical V-fold bar ring with flexible pre-stressed center for space antenna (Fraux et al. 2014) and using flexible connections in order to deploy optical reflectors (Wang et al. 2016). For large space reflectors, the Astromesh (Thomson 2000) is a widely used solution. It consists in a circular rim which is tight by wires that are actuated using electrical motors. To avoid this motorization, a family of solutions based on a scissor (Fig. 1) structure and flexible joints has been developed at LMGC (Quirant 2011) using flexible joints that deploy the structure automatically by releasing elastic energy.

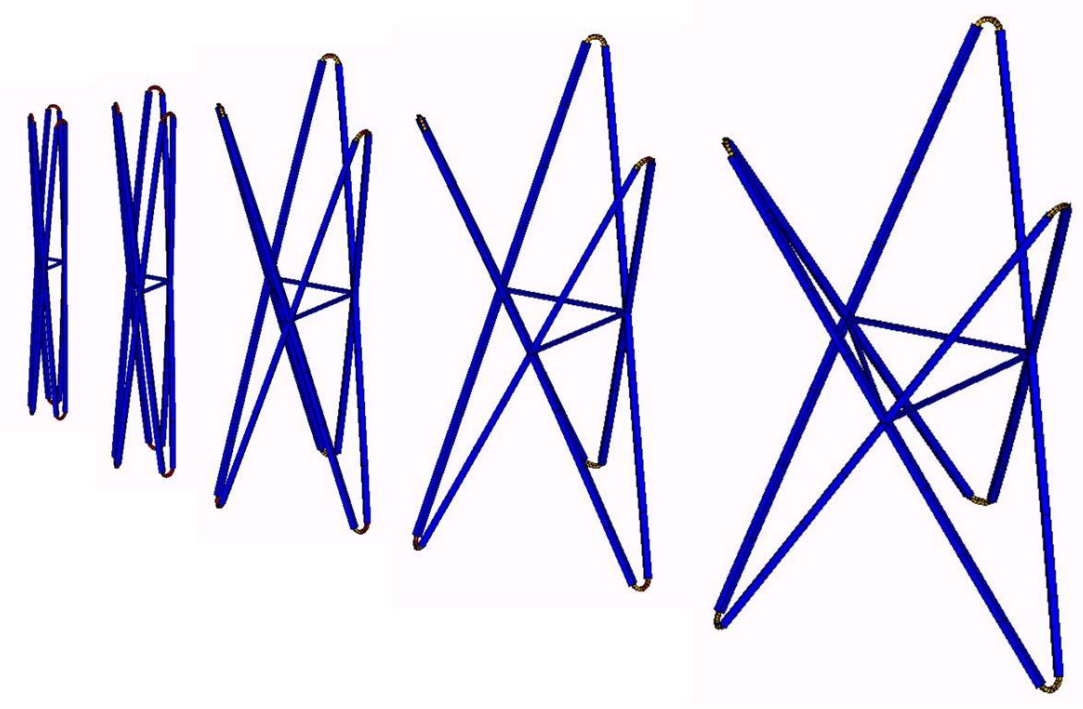

Fig. 1. Self-deployable scissor structure module using flexible joints deployment 
By increasing the number of scissors, it is possible to generate a circular structure that can tense a parabolic network of cables, realizing a mesh reflector. Following numerical simulations (statics, kinematics, modal analysis), a prototype (Fig. 2) was realized at LMGC to validate the concept (Morterolle et al. 2015).

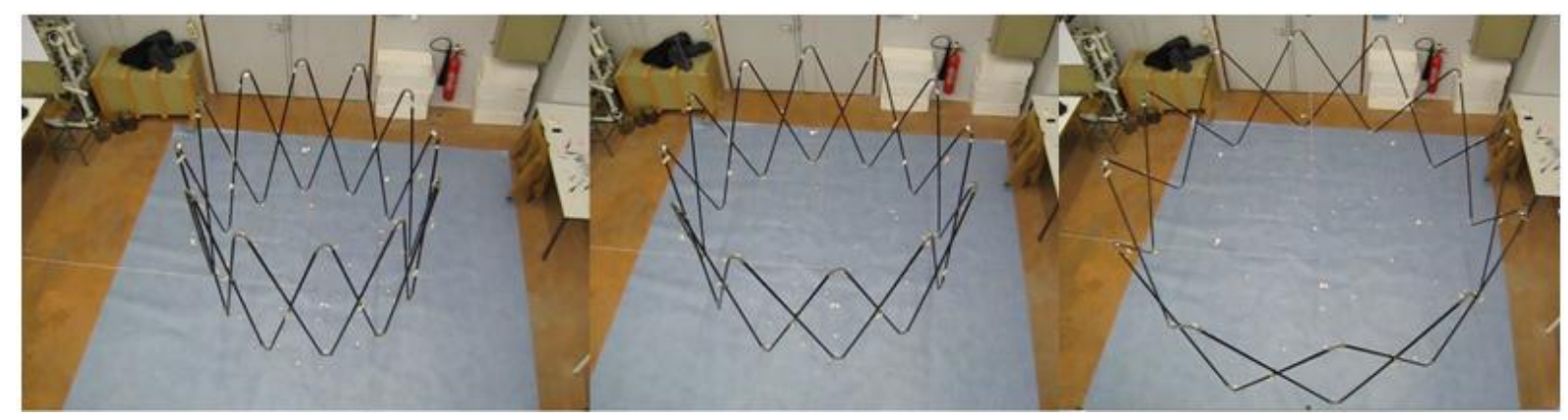

Fig. 2. Deployment of a structure made of scissors with flexible joints (LMGC)

To minimize the complexity of the articulation between elements in scissor, thus simplifying the structure and reducing the weight, we developed a new solution based on the same deployment principle, using stored elastic energy. The basic module is constituted by 4 linear beams, 4 short flexibles ones used as flexible joints, and 4 tensile wires limiting the deployment, the whole forming a "tetrahedron" (Fig. 3).
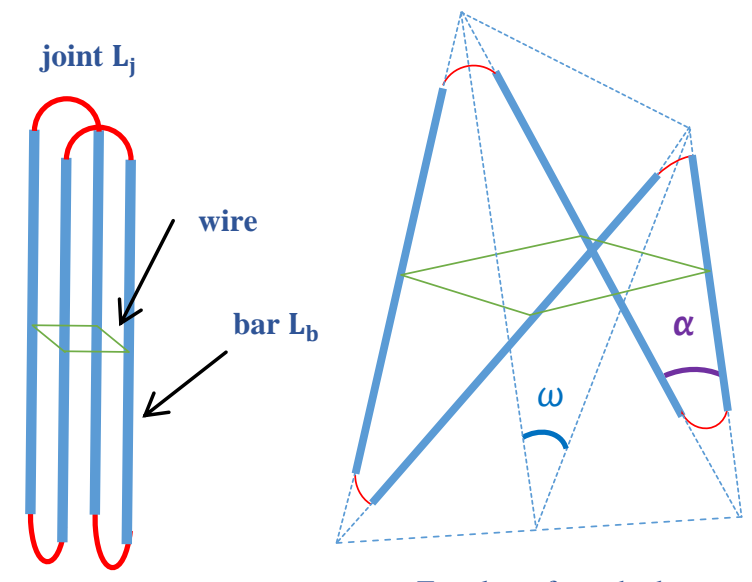

Envelop of tetrahedron

Fig. 3. Initial and last step ( $\omega$ fixed) of the deployment of a basic tetrahedron module

The main interests of this new structure is that the deployment can be total (flat configuration) 
or partial (volumic configuration), depending on the wire length. A physical model is presented in Fig. 4 with aluminum bars and flexible joints made of steel cables.
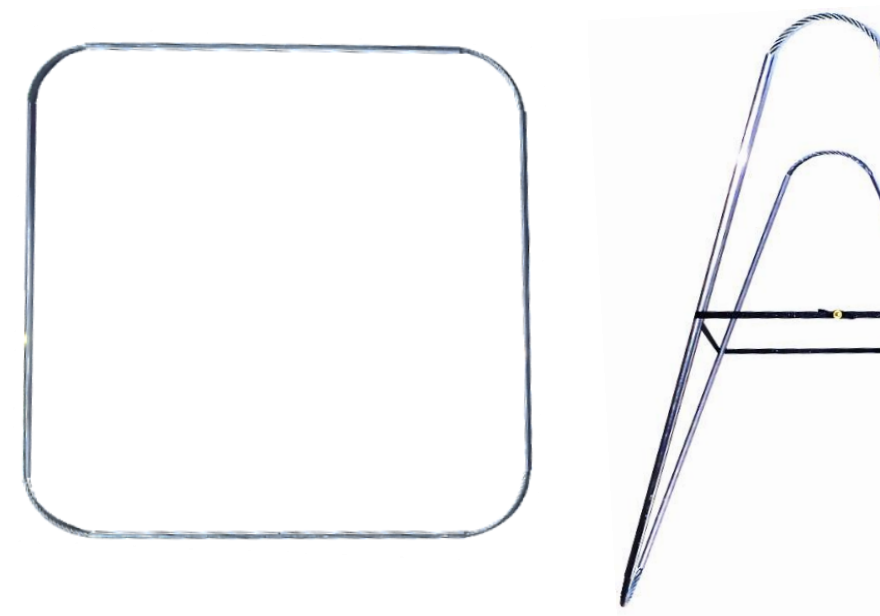

Fig. 4. Basic module - Phases of deployment, stowed, volumic and flat configurations

In the following, we study in the case of a volumic configuration, the juxtaposition of basic elements allow to generate stiff structures. For flat configuration, important surfaces can be occupied while minimizing the initial dimensions in the folded state.

\section{Geometry and configurations}

According to the desired geometry, the structure can be adapted. Two solutions may be envisaged:

- Volumic shape, which can be used to form a grid by repetition and juxtaposition, to create the support of a space antenna or solar panels.

- Outer ring structure for solar sails or space antenna applications. The number and the size of bars are optimized to generate the targeted area. 


\section{General parameters of the deployment}

As seen in Fig. 3, the elementary module is made of 4 bars, 4 joints and 4 wires. The parameters that determine the geometry of the deployment are $\alpha$ and $\omega$, where $\alpha$ is the angle between two consecutive bars, and $\omega$ the angle between the planes defined by the joints. The relation between $\alpha$ and $\omega$ is given by Eq. 1 .

$$
\omega=2 \arcsin \left(\tan \left(\frac{\alpha}{2}\right)\right)
$$

Other parameters define the geometry:

- $\mathrm{L}_{\mathrm{b}}$ is the length of the bars,

- $\mathrm{L}_{\mathrm{joint}}$ is the developed length of the joints,

- $\mathrm{R}_{\text {init }}=\mathrm{L}_{\text {joint }} / \pi$ is the radius of joint in folded configuration.

In the aim of controlling the deployment, it is needed to determine the angle of aperture $\omega$ according to the length $\mathrm{L}_{\mathrm{w}}$ of control (Fig. 5) that maintain the module partially open.
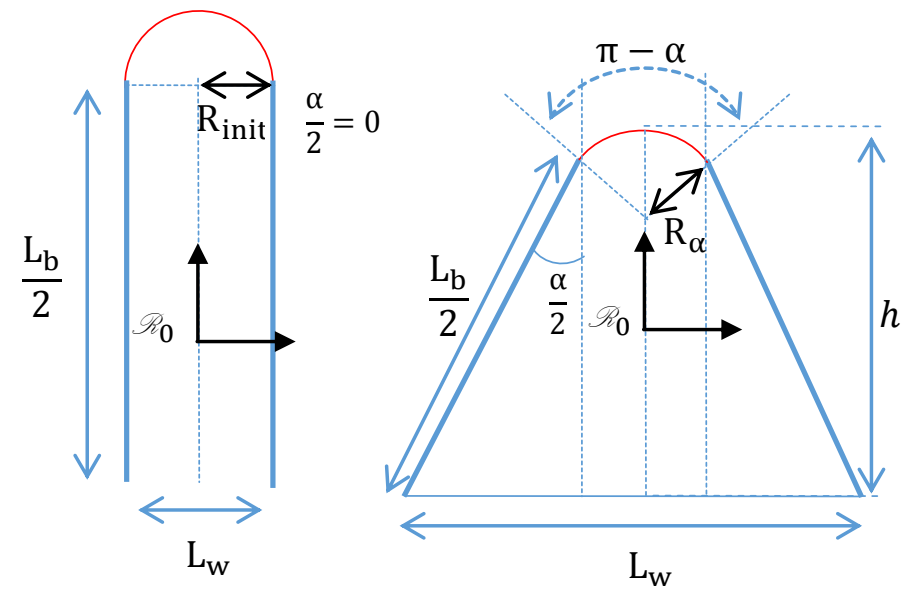

Fig. 5. Geometrical parameters in the stowed $(\alpha=0)$ and partially open configurations.

We define by Eq. 2 the radius of the circular arc of the joint in the deployed configuration. 


$$
\mathrm{R}_{\alpha}=\frac{\pi \mathrm{R}_{\text {init }}}{\pi-\alpha}
$$

The length of the wire maintaining the module is obtained by Eq.3.

$$
\mathrm{L}_{\mathrm{w}}=\mathrm{L}_{\mathrm{b}} \sin \left(\frac{\alpha}{2}\right)+2 \mathrm{R}_{\alpha} \cos \left(\frac{\alpha}{2}\right)
$$

Given the radius $R_{\alpha}$ and the length $L_{b}$ of bars, we can, demonstrate that $L_{w}$ is a monotic function of $\alpha \in\left[0, \pi\left[\right.\right.$ which means that the length $\mathrm{L}_{\mathrm{w}}$ can be defined uniquely of the desired configuration, characterized by a unique $\alpha$.

\section{Volumic deployment}

In space applications, it is essential to know at every step of the deployment the volume of the structure to control the kinetics and avoiding collisions. In function of the aperture of the structure, defined by the parameter $\alpha$ or $\mathrm{L}_{\mathrm{w}}$, it is possible to obtain either a volume or either a flat surface when fully deployed. The volume of the structure can be approximated by an enveloping tetrahedron (Fig. 3), or truncated forms when taking into consideration the volume corresponding to the connections (Fig. 6).
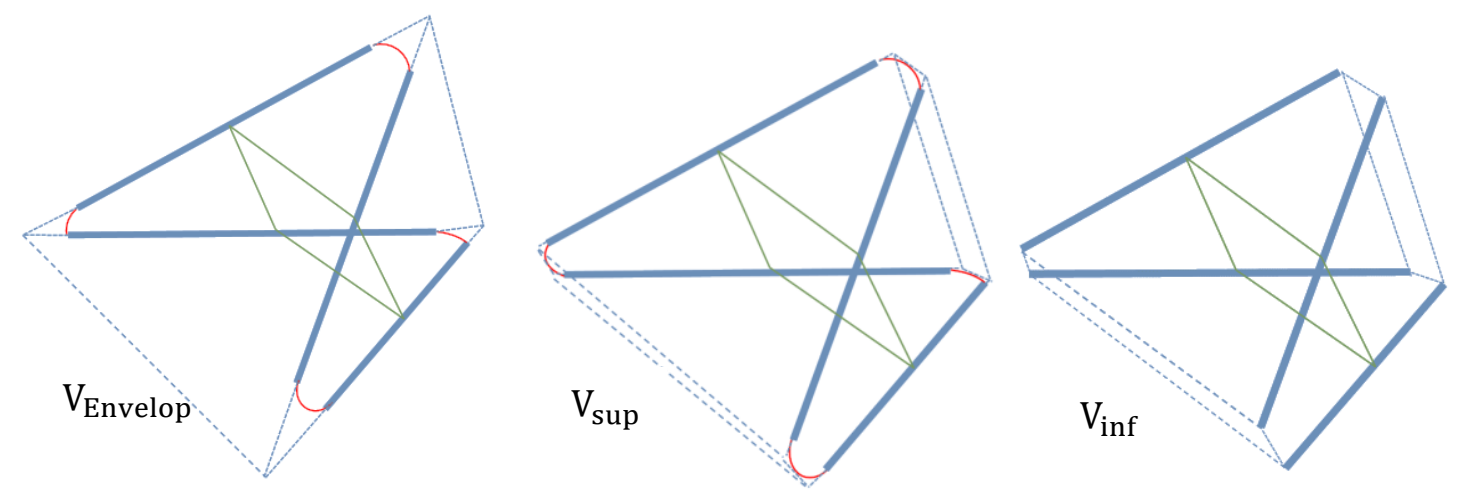

Fig. 6. Different approaches to determine the volume of a module.

The 3 corresponding expressions are given by Eq.4 to Eq.6. 


$$
\mathrm{V}_{\mathrm{env}}=\frac{2}{3} \Omega_{\alpha}\left(2 \phi_{\alpha}+\mathrm{L}_{\mathrm{b}}\right)^{3}
$$

$$
\mathrm{V}_{\mathrm{inf}}=\lambda \cdot \Omega_{\alpha}
$$

$$
\mathrm{V}_{\text {sup }}=\mu . \Omega_{\alpha}
$$

Where,

$$
\begin{gathered}
\lambda=\psi_{\alpha}-4 \phi_{\alpha}{ }^{2}\left(\mathrm{~L}_{\mathrm{b}}+\frac{4}{3} \phi_{\alpha}\right) \\
\mu=\psi_{\alpha}-4 \tau_{\alpha}{ }^{2}\left(\mathrm{~L}_{\mathrm{b}}+\frac{4}{3} \phi_{\alpha}+\frac{2}{3} \mathrm{R}_{\alpha}\left(\frac{1-\sin \left(\frac{\alpha}{2}\right)}{\cos \left(\frac{\alpha}{2}\right)}\right)\right) \\
\Omega_{\alpha}=\sin ^{2}\left(\frac{\alpha}{2}\right) \sqrt{\cos (\alpha)} \\
\psi_{\alpha}=\frac{2}{3}\left(2 \phi_{\alpha}+\mathrm{L}_{\mathrm{b}}\right)^{3} \\
\phi_{\alpha}=\frac{\mathrm{R}_{\alpha}}{\tan \left(\frac{\alpha}{2}\right)} \\
\tau_{\alpha}=2 \mathrm{R}_{\alpha} \frac{1-\sin \left(\frac{\alpha}{2}\right)}{\sin (\alpha)}
\end{gathered}
$$

Fig. 7 illustrates the variation of these 3 expressions in function of the angle $\alpha$, in the case of 
$\mathrm{L}_{\mathrm{b}}=0,48 \mathrm{~m}$ and $\mathrm{R}_{\mathrm{init}}=3 \mathrm{~cm}$. For small angles, $V_{\text {Envelop }}$ overestimates to a great extent the real volume of the module. So we therefore consider that a good approximation of the volume of the tetrahedron is ranged by $\left[\mathrm{V}_{\text {inf }} ; \mathrm{V}_{\text {sup }}\right]$. We observe also that the maximum volume is obtained for $\alpha=66^{\circ}$. Naturally, the flat configuration corresponds to $\alpha=90^{\circ}$.

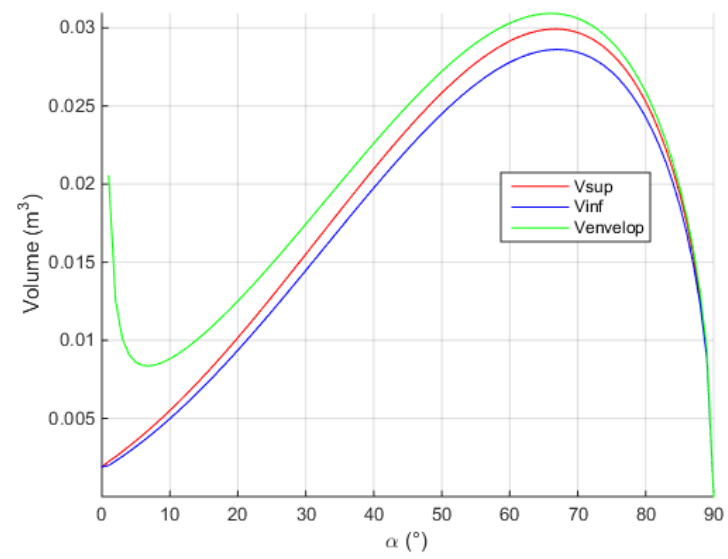

Fig. 7. Tetrahedron envelop volume

By duplicating tetrahedrons, a self-deployable grid can be formed. Similarly, Zhang (Zhang et al. 2016) presents a single truss layer made of triangular modules where each bar is made of two equal articulated parts that deploy using a flexible joint (torsional spring). In our case, the assembly of several tetrahedrons forms an auto-deployable structure usable as plan support for reflectors or solar panels (Fig. 8) choosing or not the maximum of the volume for the structure.

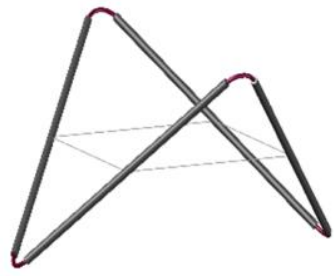

Tetrahedron

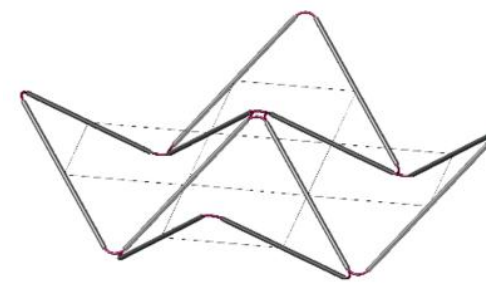

Assembly of 4 tetrahedrons

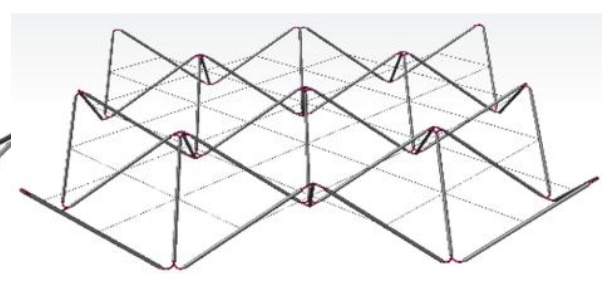

Truss of many assemblies

Fig. 8. Assembly of tetrahedrons 


\section{Deployment of an assembly of 4 modules}

Compared to a module, the assembly of several modules permits to expand the usable area. Using numerical simulations, we chose as geometrical convergence parameter $\mathrm{L}_{\mathrm{w}}=\mathrm{L}_{\mathrm{b}} / 2$.
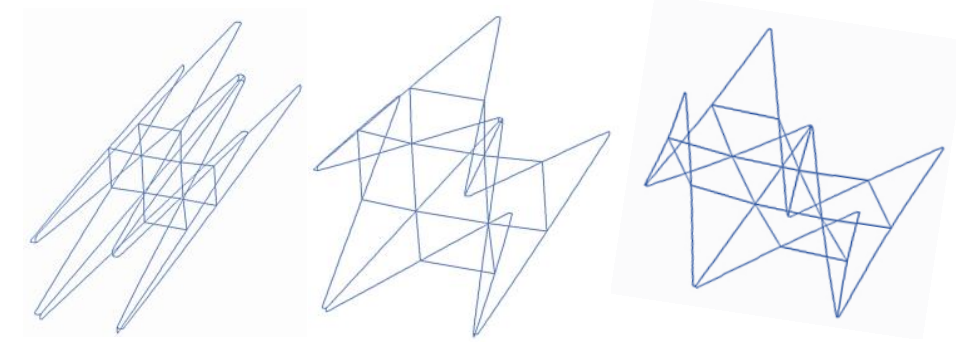

Fig. 9. Progressive steps in the deployment of an assembly of 4 modules

Fig. 9 shows the steps of the deployment of an assembly of 4 tetrahedron. As shown in Fig.

10, this kind of structure can be used as support for solar panel, or space antenna.
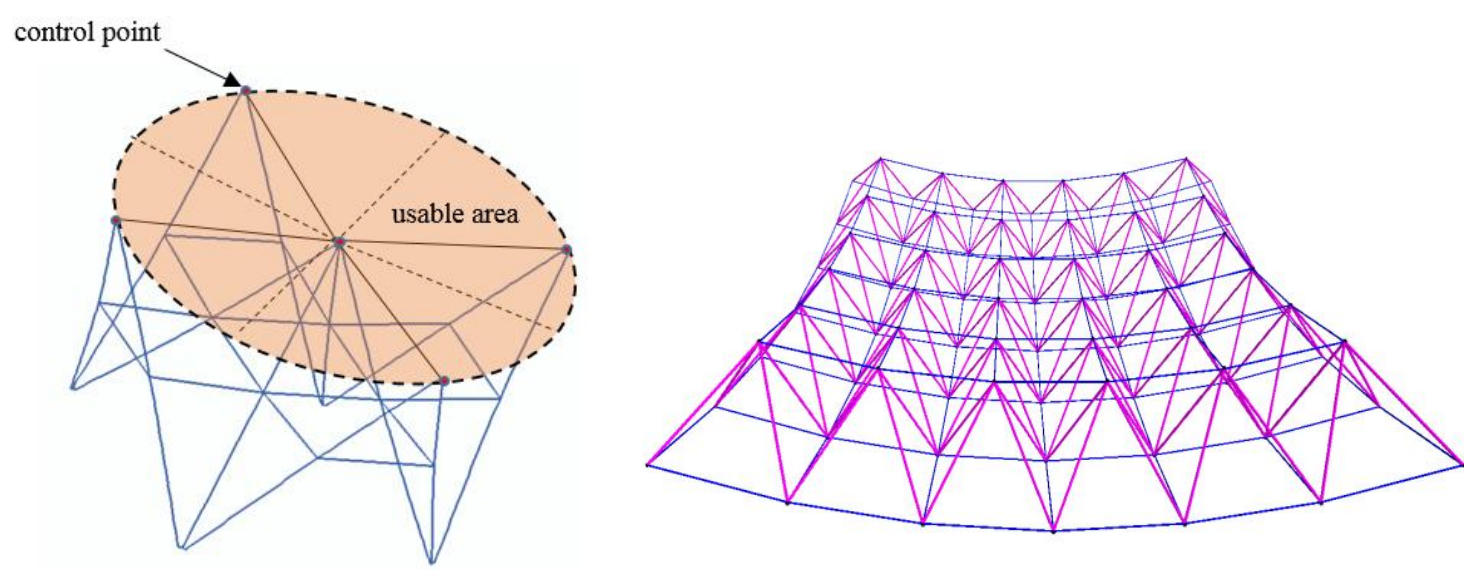

Fig. 10. Assembly of 4 modules and grid usable area.

\section{Circular deployment}

By lengthening the restraining wire of a module at its maximum, we obtain a flat square as presented in Fig. 4 (right). Using the same structural principle, we can generate a quasicircular shape by increasing the number of bar-joint sets, so as to form a regular polygonal 
ring (Fig. 11) with $\mathrm{N}$ sides. Actually, larges spaces antennas are composed of a circular rim that allows to put in tension a cable net. $\mathrm{Xu}(\mathrm{Xu} 2012)$ has developed a structure made by many trusses forming a toroidal rim at the deployed configuration. Viquerat (Viquerat et al. 2013) also proposes rings with a flat polygon shape and oriented joints, which differs from our polygonal structure composed of non-oriented flexible connections. Mouthuy (Mouthuy et al. 2012) presents an analytical model of the buckling and folding of a ring made of only one flexible element, presenting a low rigidity for space applications. In order to obtain a folding symmetry and a sufficient rigidity, we propose self-deployable polygonal ring with several bars and flexible connections.

Fig. 11. Steps of deployment for a N-bars flat structure

\section{Number of bars for a desired area}

In the flat geometry, the polygonal area A can be estimated as:

$$
A=\frac{N_{b}{ }^{2}}{4 \tan \left(\frac{\pi}{N}\right)}
$$

In order to determine the necessary number of bars $\mathrm{N}$ necessary to cover a required area, and using bars with a given length $\mathrm{L}_{\mathrm{b}}$ we use a Taylor- $3^{\text {rd }}$ order limited development of $\tan \left(\frac{\pi}{\mathrm{N}}\right)$, which leads to an approximation $\mathrm{A}^{\text {approx }}$ of the desired area A, (Eq.14).

$$
A^{\text {approx }}=4 \frac{N^{4} L_{b}{ }^{2}}{\pi N^{2}+\frac{\pi^{3}}{3}}
$$

From this equation, we can deduce the expression of the number of bars $\mathrm{N}$ in function of $\mathrm{A}$ 
and $\mathrm{L}_{\mathrm{b}}$ (Eq.15).

$$
N(\zeta)=\left\lceil\sqrt{\frac{2 \pi}{\zeta}\left(1+\sqrt{1+\frac{\zeta \pi}{3}}\right)}\right\rceil
$$

In this expression, $\zeta=\mathrm{L}_{\mathrm{b}}{ }^{2} / \mathrm{A}$ and $\lceil\mathbf{x}\rceil$ denotes the integer part of $\mathbf{x}$ rounded up to the superior unit. To insure the folding, other required conditions are that this number of bars needs to be even and strictly upper than 2 .

For a prescribed bar length $L_{b}$, the relative approximation error $\left(A-A^{\text {approx }}\right) / A$ can be estimated by Eq.16.

$$
e(N)=1-\frac{16 N^{3}}{\pi N^{2}+\frac{\pi^{3}}{3}} \tan \left(\frac{\pi}{N}\right)
$$

Eq.16 is usable for any $\mathrm{L}_{\mathrm{b}}$ and any $\mathrm{N} \geq 4$. The value $\mathrm{e}(\mathrm{N})$ never exceed $5.6 \%$, and stays below $1 \%$ from $\mathrm{N} \geq 8$, demonstrating high confidence in Eq.14 and Eq.15. For the design, we present in Fig.12 the desired bar number in function of $A$ and $L_{b}$, permitting to find the appropriate dimensions for the structure.

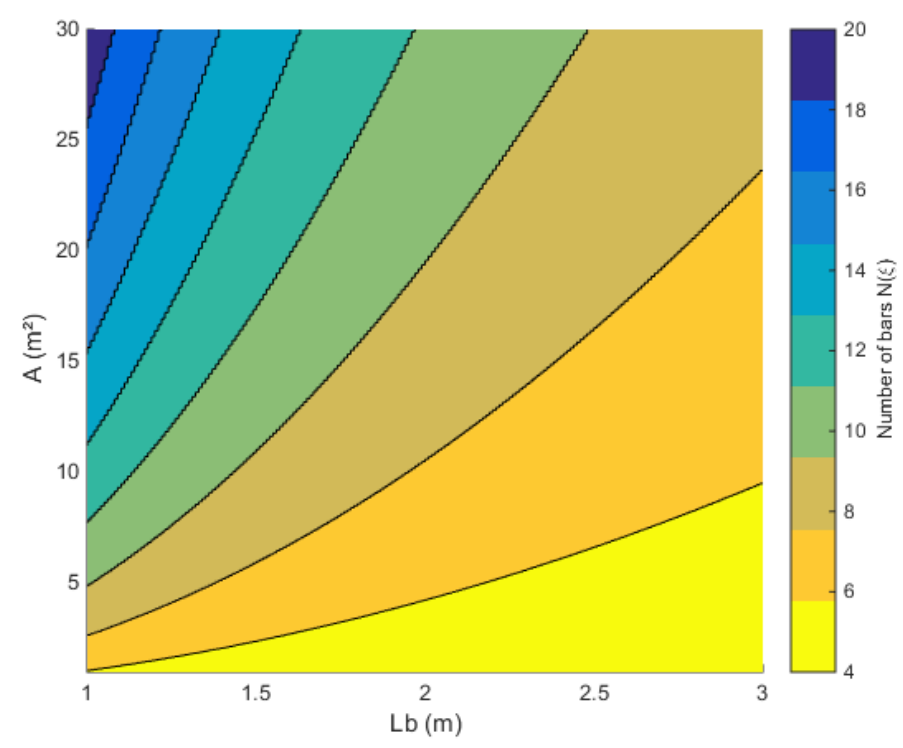

Fig. 12. Number of bars $\mathrm{N}$ in function of $\mathrm{A}$ and $\mathrm{L}_{\mathrm{b}}$ 
In order to get more compactness, it is possible to pack the bars in two different arrangements.

In a first configuration (Fig. 13.a), bars are distributed along a circle, and deploy themselves in one phase, as in Fig. 11. A second possibility is the case where bars are arranged on two concentric circles (Fig. 13.b), which necessitates a two-phase deployment as presented in the following paragraph.

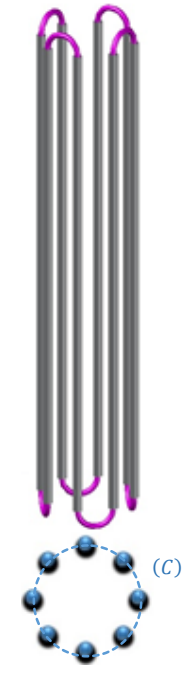

(a)

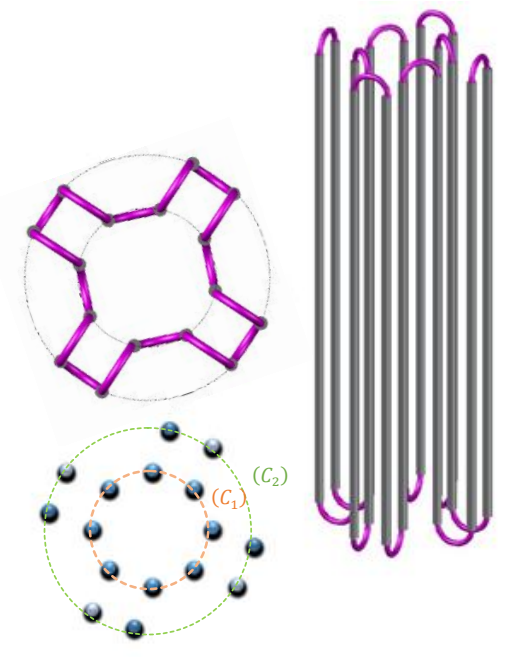

(b)

Fig. 13. Schema for a "one circle" configuration (a) "two circles" configuration (b)

To permit the deployment of the (b) configuration, the number of bar has to be a multiple of 4.

\section{"One circle" configuration}

To insure that the structure is not too voluminous, some geometrical constraints about the stowed configuration are to be considered.

In this case, we suppose that the structure is stowed inside a cylinder or radius storage (Fig. 
14).

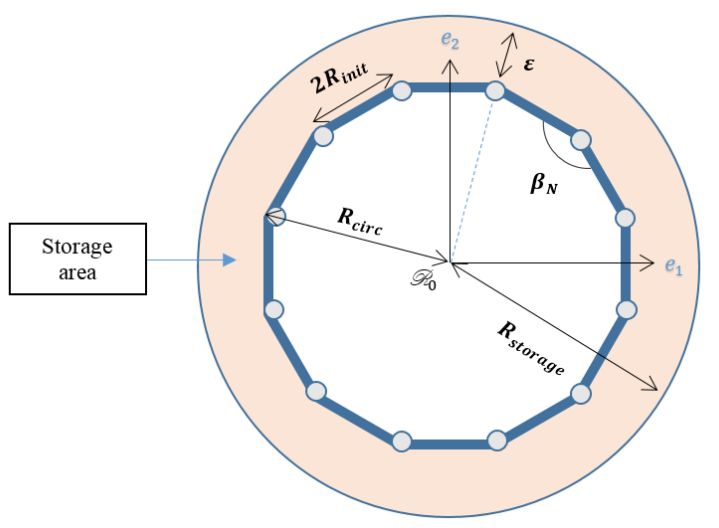

Fig. 14. Cross section of the stowed structure

Besides, the angle between two sides of the polygon is given by Eq.17.

$$
\beta_{\mathrm{N}}=\frac{\mathrm{N}-2}{\mathrm{~N}} \pi, \quad \forall \mathrm{N} \in \mathbb{N}, \quad \mathrm{N} \geq 4
$$

Fig. 15 represents an expansion of a portion of Fig. 14 where the radius $R_{\text {circ }}$ of the stowed structure, which is expressed by Eq.18, is imposed.

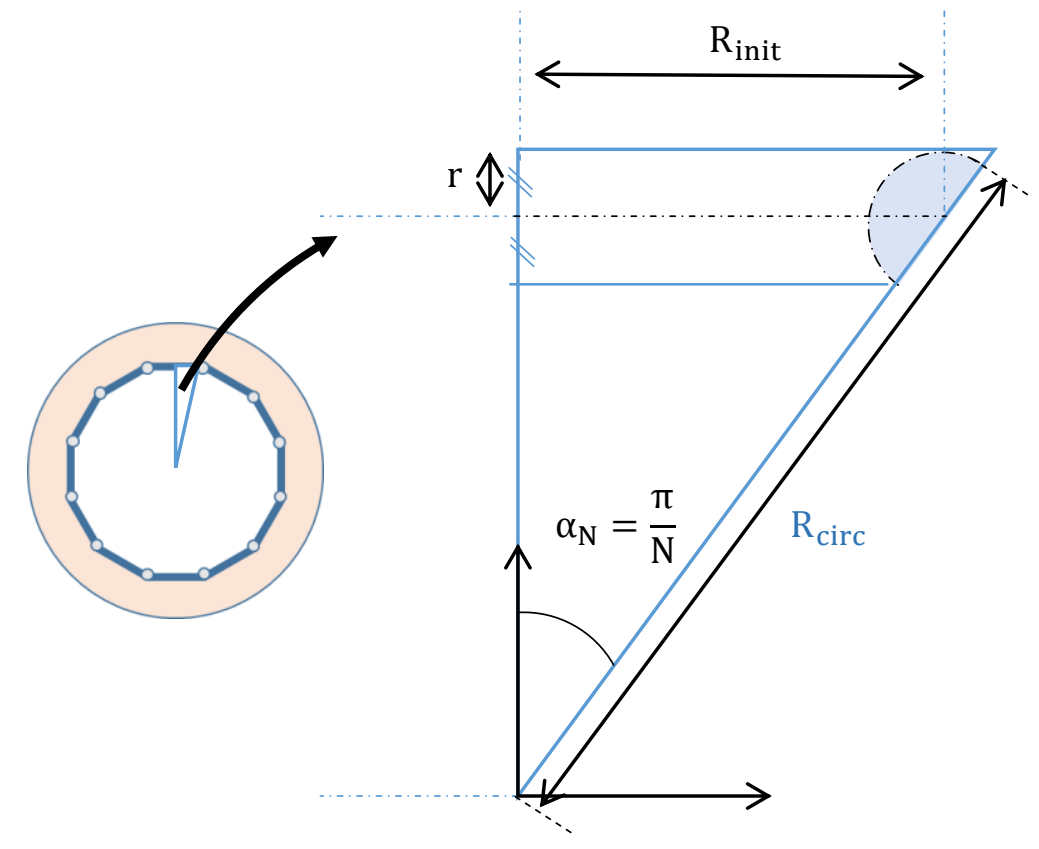

Fig. 15. Portion of the cross section of the stowed structure 


$$
\mathrm{R}_{\operatorname{circ}}=\frac{\mathrm{R}_{\text {init }}}{\sin \left(\frac{\pi}{\mathrm{N}}\right)}+\mathrm{r}
$$

A first condition is given by the needed clearance $(\varepsilon)$ between the radius of the storage area $\left(\mathrm{R}_{\text {storage }}\right)$ and $\left(\mathrm{R}_{\text {circ }}\right)$ of the folded structure:

$$
\mathrm{R}_{\text {circ }}=\mathrm{R}_{\text {storage }}-\varepsilon, \quad \forall \mathrm{N} \in 4 \mathbb{N}^{*}
$$

The second condition imposed a maximum radius for bars and joint, in order to avoid contact between the bars $\left(r \leq \mathrm{R}_{\text {init }}\right)$. We deduce the inequation of the geometrical constraint of the radius of a bar:

$$
0<r \leq \mathrm{R}_{\text {init }} \leq \frac{\mathrm{R}_{\text {circ }} \sin \left(\frac{\pi}{\mathrm{N}}\right)}{1+\sin \left(\frac{\pi}{\mathrm{N}}\right)}
$$

An application to a CubeSat's deorbiting sail and a coverable surface of $1 \mathrm{~m}^{2}$ with a storage volume authorized, of $3 \times 3 \times 10 \mathrm{~cm}^{3}, \varepsilon=0$ and $\mathrm{N}=36$, the maximal radius of a bar is $\mathrm{r} \leq 1,2 \mathrm{~mm}$.

\section{"Two circles" configuration}

For a same bar number, the radius of a 1-circle configuration is noted $R_{c}$ and that of a 2circles stowed configuration is $\mathrm{R}_{\mathrm{c} 2}$ as shown in Fig. 16 .

Analytically $\mathrm{R}_{\mathrm{c}}$ and $\mathrm{R}_{\mathrm{c} 2}$ are expressed by Eq.21 and Eq.22, respectively

$$
\begin{gathered}
\mathrm{R}_{\mathrm{c}}=\frac{\mathrm{R}_{\text {init }}}{\sin \frac{\pi}{\mathrm{N}}} \\
\mathrm{R}_{\mathrm{c} 2}=\mathrm{R}_{\text {init }} \sqrt{\left(\frac{1}{\tan \frac{2 \pi}{N}}+2\right)^{2}+1}
\end{gathered}
$$




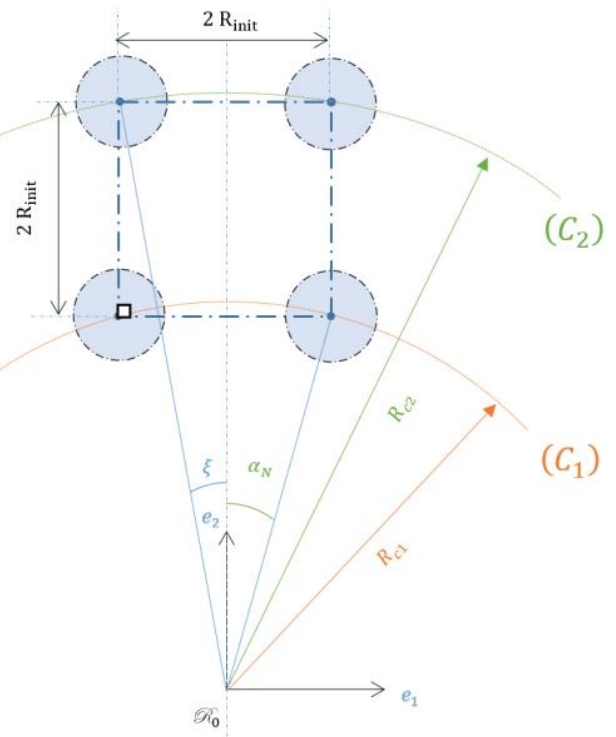

Fig. 16. Geometry of the 2-circles arrangement

Numerically, (see Fig. 17), we demonstrate that $R_{c}=R_{c 2}$ when $N=12$ and $R_{c}>R_{c 2}$ when $\mathrm{N}$ gets higher than 12 . We can demonstrate analytically that the ratio tends toward 0 when $\mathrm{N}$ tends to infinity. For a higher number of bars, the 2-circle configuration is more efficient in term of initial compacteness than the 1-circle one. For a structure made of 24 bars, the 2circles arrangement allows $25 \%$ lower of stowed radius than 1-circle configuration.

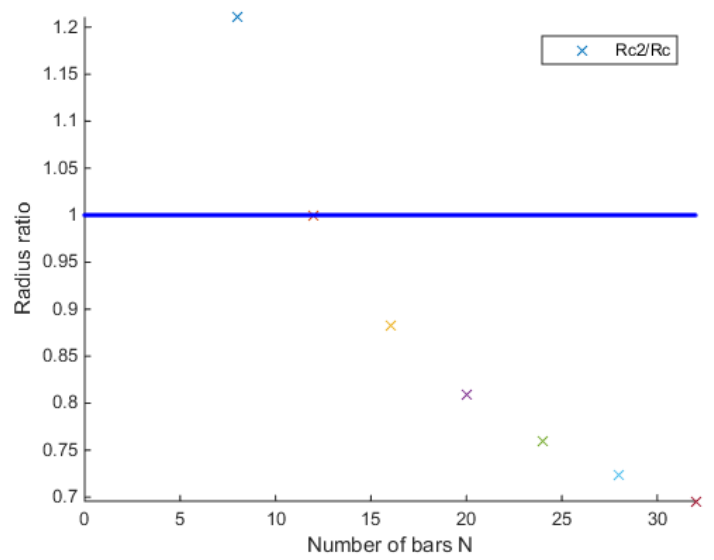

Fig. 17. Ratio of the radiuses of 2-circle configuration by 1-circles configuration in function of $\mathrm{N}$ 
As defined previously, the geometrical constraint on the radius of a bar for a 2-circles configuration is given by Eq.23

$$
0<\mathrm{r}_{2} \leq \mathrm{R}_{\text {init }} \leq \frac{\mathrm{R}_{\text {circ2 }}}{1+\sqrt{\left(\frac{1}{\tan \left(\frac{2 \pi}{\mathrm{N}}\right)}+2\right)^{2}+1}}
$$

$\mathrm{R}_{\text {circ2 }}=\mathrm{R}_{\mathrm{c} 2}+\mathrm{r}_{2}=\mathrm{R}_{\text {storage }}-\varepsilon$.
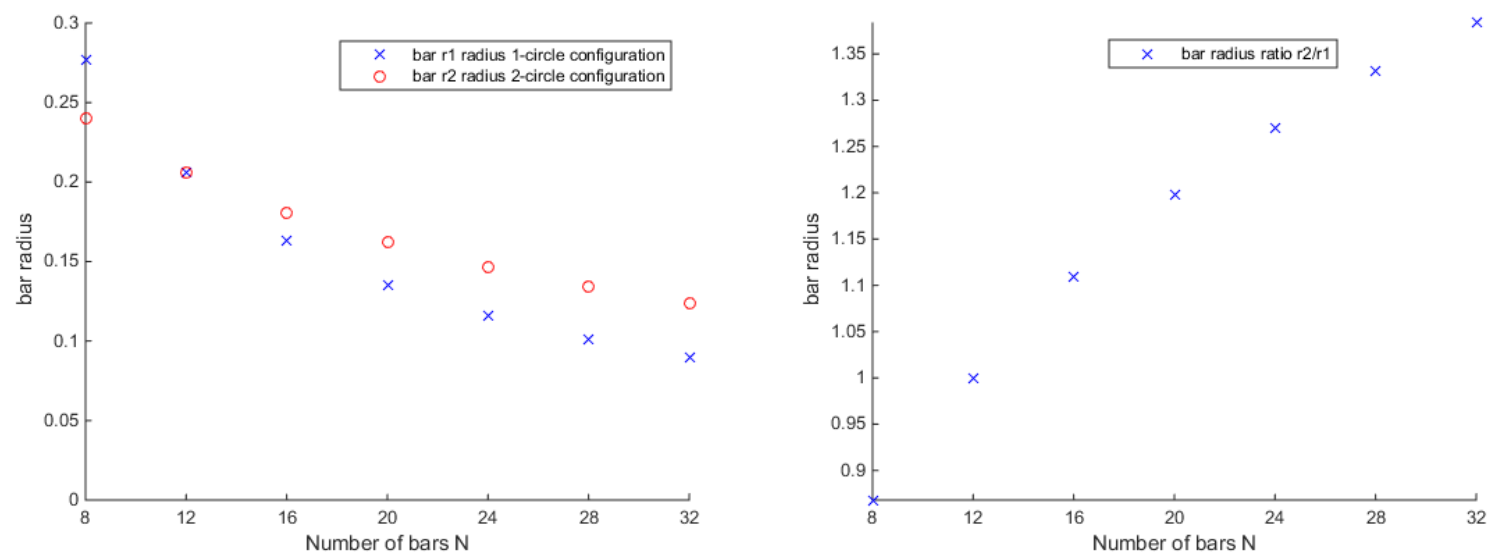

Fig. 18. Comparison between the maximum radiuses of the bars for the two configurations

$$
\text { with } \mathrm{R}_{\mathrm{c} 2}=1 \mathrm{~m}
$$

$\mathrm{r}_{1}=$ maximum radius of a bar of 1-circle configuration

$\mathrm{r}_{2}=$ maximum radius of a bar of 2-circle configuration

As seen Fig. 18, for the same initial compactness, the geometrical constraint equation of the radius of a bar $r_{1}$ is more restrictive than for $r_{2}$.

For illustration of this packing solution, we consider a 16 bars structure distributed on 2 circles. The deployment begins in a first step (Fig. 19 Step 1) by an alignment of the bars present on the first circle with the other bars. The second step consist in an unlocking of all nodes (Fig. 19 Step 2) to finally obtain a ring. In this case, the packed radius $\mathrm{Rc}_{2}$ is $75 \%$ of 
the $\mathrm{R}_{\mathrm{c}}$ the same $\mathrm{N}$ bars.

\section{Step 1}
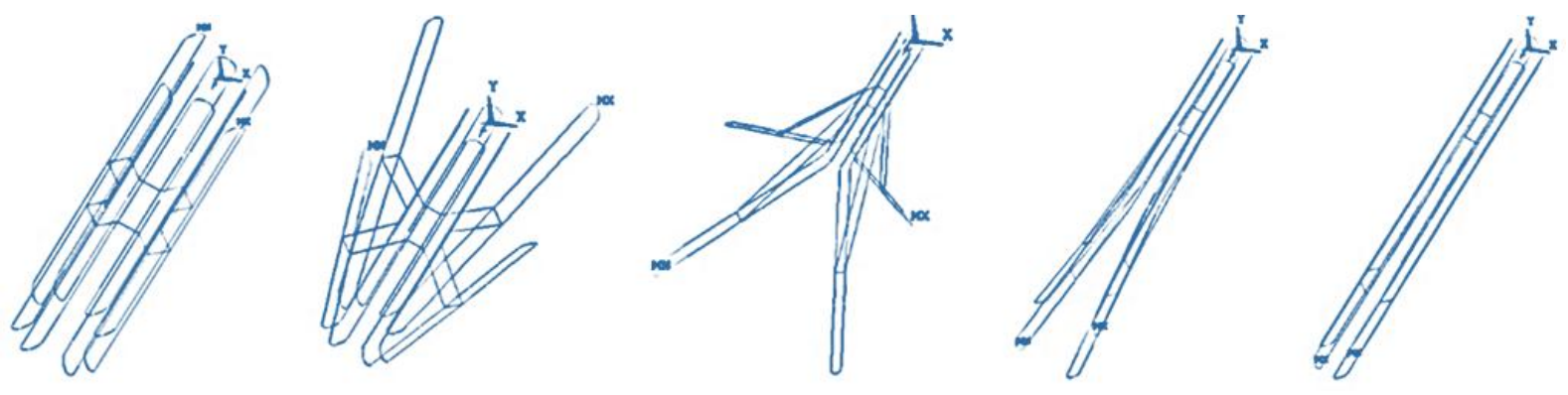

Step 2
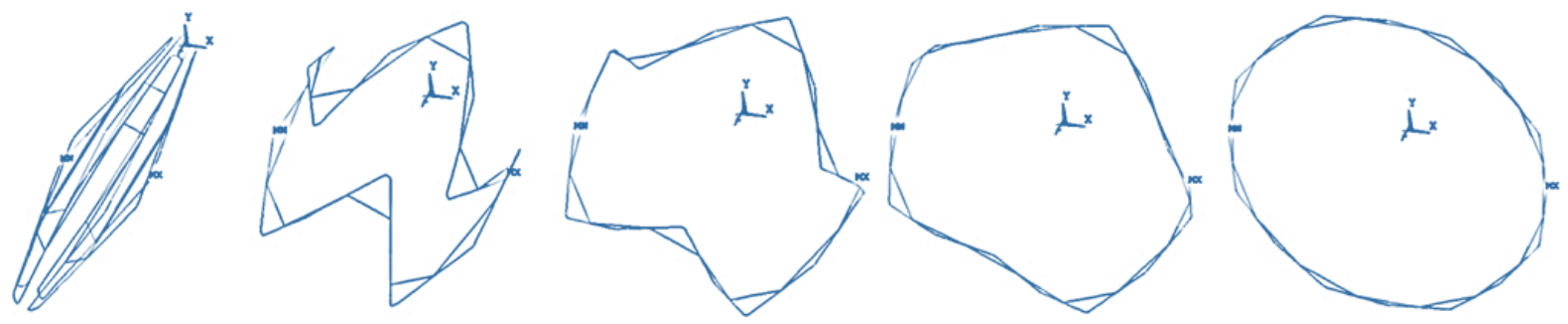

Fig. 19. Two stage of deployment of the ring for a 2 circle configuration

\section{Static and dynamic analysis}

In order to get insights on internal forces and design conditions, we study the equilibrium of a module during the deployment.

\section{Tetrahedron equilibrium}

Let $\mathscr{R}_{0}$, defined by $\left[\mathrm{e}_{1}, \mathrm{e}_{2}, \mathrm{e}_{3}\right]$ the canonical basis of $\mathbb{R}^{3}$ and $\mathcal{O}(3, \mathbb{R})$ the orthogonal group of the direct rotations, with the origin positioned at the center of the structure defined by the center of the square formed by the wire (Fig. 20).

Since there exists two planes of symmetry $\left(\mathrm{e}_{1}, \mathrm{e}_{3}\right)$ and $\left(\mathrm{e}_{2}, \mathrm{e}_{3}\right)$, we can consider only the equilibrium of two consecutive bars. Using the notations introduced in Fig. 3 and Eq. 1, 
$\omega=\left(\overrightarrow{\mathrm{P}_{0} \mathrm{P}_{\mathrm{A}}}, \overrightarrow{\mathrm{P}_{0} \mathrm{P}_{\mathrm{B}}}\right)$ is the oriented aperture angle and $\alpha=\left(\overrightarrow{\mathrm{P}_{\mathrm{L}} \mathrm{P}_{\mathrm{A}}}, \overrightarrow{\mathrm{P}_{\mathrm{L}} \mathrm{P}_{\mathrm{B}}}\right)$ the oriented angle between two consecutives bars.

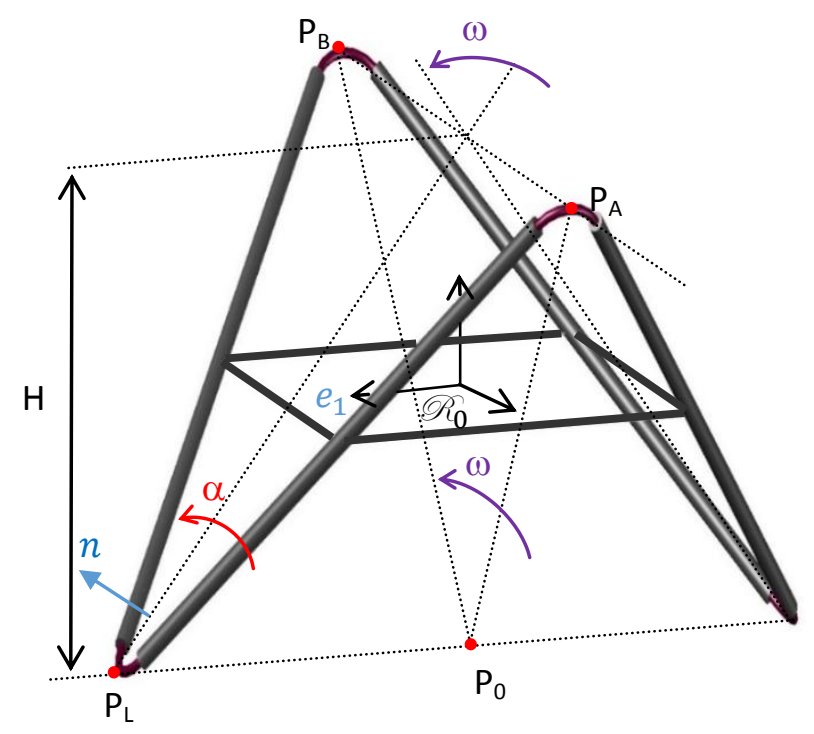

Fig. 20. Parameters for static equilibrium study

In the $\mathscr{R}_{0}$ global coordinate system, we denote by $\mathrm{F}_{\mathrm{e}_{\mathrm{i}}}$ and $\mathrm{M}_{\mathrm{e}_{\mathrm{i}}}$ respectively the effort and the moment supported by $e_{i}$ where $i=\{1,2,3\}$. The torsor of cohesion in the joint cut at node $P_{A}$ by plane $\left(e_{2}, e_{3}\right)$ is given by:

$$
\left[\tau_{\operatorname{coh} 1}\right]=\left[\begin{array}{ll}
F_{\mathrm{e}_{1}} & \mathrm{M}_{\mathrm{e}_{1}} \\
\mathrm{~F}_{\mathrm{e}_{2}} & \mathrm{M}_{\mathrm{e}_{2}} \\
\mathrm{~F}_{\mathrm{e}_{3}} & \mathrm{M}_{\mathrm{e}_{3}}
\end{array}\right]
$$

Similarly, and due to the symmetry $\left(\mathrm{e}_{1}, \mathrm{e}_{3}\right)$, the torsor of cohesion at node $\mathrm{P}_{\mathrm{B}}$ is:

$$
\left[\tau_{\operatorname{coh} 2}\right]=\left[\begin{array}{cc}
\mathrm{F}_{\mathrm{e}_{1}} & -\mathrm{M}_{\mathrm{e}_{1}} \\
-\mathrm{F}_{\mathrm{e}_{2}} & \mathrm{M}_{\mathrm{e}_{2}} \\
\mathrm{~F}_{\mathrm{e}_{3}} & -\mathrm{M}_{\mathrm{e}_{3}}
\end{array}\right]
$$

With $\mathrm{T}$ the tension in wire, the force vectors $\mathrm{T}_{1}$ and $\mathrm{T}_{2}$ introduced by wires at nodes $\mathrm{O}_{\mathrm{A}}$ and $\mathrm{O}_{\mathrm{B}}$ (in the middle of the bars) are: 


$$
\left\{\mathrm{T}_{1}\right\}=\left\{\begin{array}{c}
-\mathrm{T} \\
-\mathrm{T} \\
0
\end{array}\right\} \quad \text { and } \quad\left\{\mathrm{T}_{2}\right\}=\left\{\begin{array}{c}
-\mathrm{T} \\
\mathrm{T} \\
0
\end{array}\right\}
$$

When cutting by vertical plane $\left(\mathrm{e}_{2}, \mathrm{e}_{3}\right)$, these torsors and forces are presented in Fig. 21.

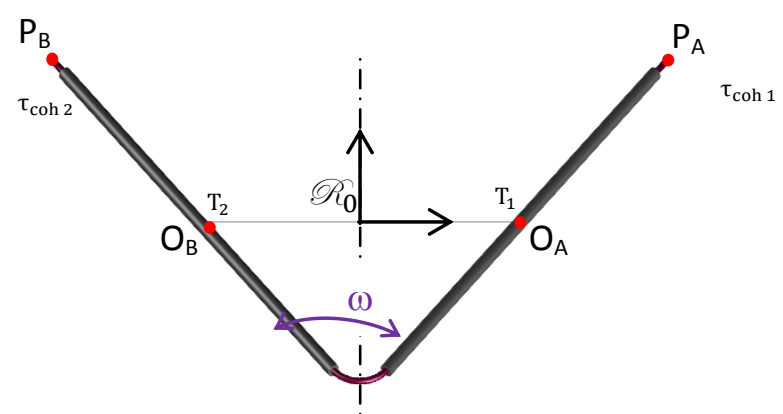

Fig. 21. Side view of the tetrahedron

There is a symmetry by rotation of $180^{\circ}$ around $e_{3}$ that can be represented by matrix $\left[\mathrm{R}_{\mathrm{e}_{3}}\right]$ :

$$
\left[\mathrm{R}_{\mathrm{e}_{3}}\right]=\left[\begin{array}{ccc}
-1 & 0 & 0 \\
0 & -1 & 0 \\
0 & 0 & 1
\end{array}\right], \quad \mathrm{R}_{\mathrm{e}_{3}} \in O(3, \mathbb{R})
$$

The mechanical consequences are:

$$
\left\{\mathrm{F}_{\mathrm{P}_{\mathrm{B}}}\right\}=-\left[\mathrm{R}_{\mathrm{e}_{3}}\right]\left\{\mathrm{F}_{\mathrm{P}_{\mathrm{A}}}\right\}=\left\{\mathrm{F}_{\mathrm{e}_{1}}, \mathrm{~F}_{\mathrm{e}_{2}},-\mathrm{F}_{\mathrm{e}_{3}}\right\}^{\mathrm{t}}
$$

Where \{\}$^{\mathrm{t}}$ is the transposed operator.

Eq. 25 and Eq. 28 give:

$$
\mathrm{F}_{\mathrm{e}_{2}}=-\mathrm{F}_{\mathrm{e}_{2}}=0, \quad \mathrm{~F}_{\mathrm{e}_{3}}=-\mathrm{F}_{\mathrm{e}_{3}}=0
$$

For the moments, the symmetry leads to:

$$
\left\{\mathrm{M}_{\mathrm{P}_{\mathrm{B}}}\right\}=-\left[\mathrm{R}_{\mathrm{e}_{3}}\right]\left\{\mathrm{M}_{\mathrm{P}_{\mathrm{A}}}\right\}=\left\{\mathrm{M}_{\mathrm{e}_{1}}, \mathrm{M}_{\mathrm{e}_{2}},-\mathrm{M}_{\mathrm{e}_{3}}\right\}^{\mathrm{t}}
$$

Eq. 25 and Eq. 30 then provide:

$$
\mathrm{M}_{\mathrm{e}_{1}}=-\mathrm{M}_{\mathrm{e}_{1}}=0
$$

The equilibrium of the forces as presented in Fig. 21 gives on $e_{1}$ : 


$$
2 \mathrm{~F}_{\mathrm{e}_{1}}-2 \mathrm{~T}=0 \quad \rightarrow \quad \mathrm{F}_{\mathrm{e}_{1}}=\mathrm{T}
$$

The equilibria of the moments on $\mathrm{e}_{2}$ is:

$$
2 \mathrm{M}_{\mathrm{e}_{2}}+2 \mathrm{~T} \frac{\mathrm{H}}{2}=0 \quad \rightarrow \quad \mathrm{M}_{\mathrm{e}_{2}}=-\mathrm{T} \frac{\mathrm{H}}{2}
$$

The local moment in joints is carried by $\mathrm{n}_{\mathrm{j}}$, the normal vector to the plane defined by two successive bars (Fig. 20), and its expression is:

$$
M_{\text {joint }}=\frac{E_{\text {joint }} I_{\text {joint }}}{R_{\alpha}}
$$

Where $E_{\text {joint }}$ is the Young modulus of the joint, $I_{\text {joint }}$ the flexural moment of inertia of the joint and $\mathrm{R}_{\alpha}$ the radius of the joint defined by Eq.2.

This moment is projected on the vectors $\mathrm{e}_{2}$ and $\mathrm{e}_{3}$ as follows:

$$
\mathrm{M}_{\mathrm{e}_{2}}=\mathrm{M}_{\text {joint }} \cos \left(\frac{\omega}{2}\right)
$$

and

$$
\mathrm{M}_{\mathrm{e}_{3}}=\mathrm{M}_{\mathrm{joint}} \sin \left(\frac{\omega}{2}\right)
$$

We deduce that:

$$
\frac{\mathrm{M}_{\text {joint }}}{\mathrm{T}}=\frac{\mathrm{H}}{2 \cos \left(\frac{\omega}{2}\right)}
$$

\section{Effort and moment relations}

Using relations Eq.34 through Eq.37, it is then possible to calculate the bending moment in the joints as well as the tension in the wires at every step of the deployment. These expressions depends at the same time on characteristics of materials and of the geometry (aperture). For a given configuration, by developing Eq. 37, the static equilibrium results in Eq.38.

$$
\frac{\left|\mathrm{M}_{\text {joint }}\right|}{|\mathrm{T}|}=\left(\frac{1}{2} \mathrm{~L}_{\mathrm{b}}+\frac{\pi \mathrm{R}_{\text {init }}}{\pi-\alpha}\left(1-\sin \left(\frac{\alpha}{2}\right)\right)\right) \cos \left(\frac{\alpha}{2}\right)
$$


In Fig. 22 a representation of the tension in the wire in function of $\alpha$ is given for $L_{b}=1 \mathrm{~m}$, $\mathrm{L}_{\mathrm{a}}=3 \mathrm{~cm}$ joint diameter $\mathrm{d}_{\text {joint }}=2 \mathrm{~mm}, \mathrm{I}_{\text {joint }}=\frac{\pi \mathrm{d}^{4}}{64}$, and $\mathrm{E}_{\text {joint }}=125 \mathrm{GPa}$. Eq. 40 gives also the moment in function of $\alpha$ in the joint for the same parameters.

The analytical relation of the tension is given by:

$$
\mathrm{T}=\frac{\mathrm{E}_{\text {joint }} \mathrm{I}_{\text {joint }}}{\mathrm{R}_{\text {init }}} \frac{\left(1-\frac{\alpha}{\pi}\right)}{\left(\frac{\mathrm{L}_{\mathrm{b}}}{2}+\frac{\pi \mathrm{R}_{\text {init }}}{\pi-\alpha}\left(1-\sin \left(\frac{\alpha}{2}\right)\right)\right) \cos \left(\frac{\alpha}{2}\right)}
$$

In the same way, we define the moment in the joint by:

$$
M_{\text {joint }}=\frac{E_{\text {joint }} I_{\text {joint }}}{R_{\text {init }}}\left(1-\frac{\alpha}{\pi}\right)
$$
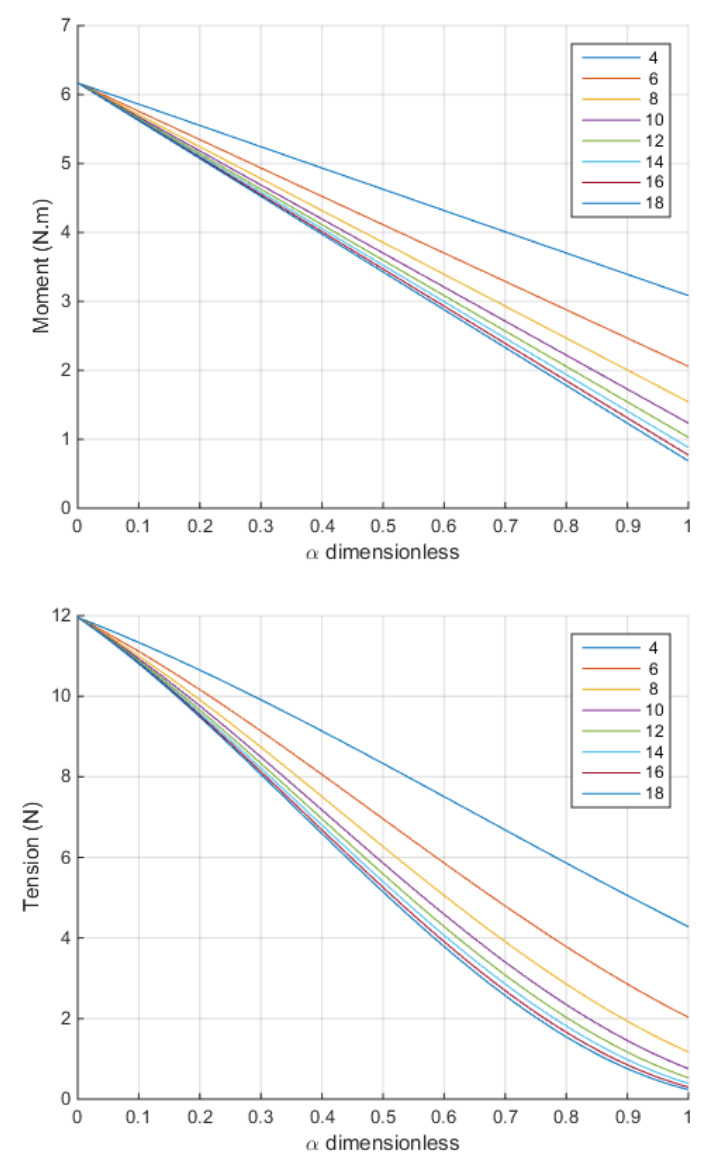

Fig. 22. Tension in wires and bending moment in joints for a given configuration 
Where $\bar{\alpha}$ is the ratio between $\alpha$ and the maximum value of $\alpha$ denoted by $\bar{\alpha}=\frac{\alpha}{\left(1-\frac{2}{N}\right) \pi}$. As shown in Fig. 22, for all N, T and $\mathrm{M}_{\text {joint }}$ are decreasing in function of $\bar{\alpha}$.

\section{Comparison between analytical model and Ansys ${ }^{\circledR}$ model}

In order to predict the behavior of the deployment of the module, we model it analytically and numerically by a FEM analysis using ANSYS ${ }^{\circ}$ software. This permits to verify the accuracy of the FEM prestressing process. The system is initially in a stowed configuration. In the simulation, every bar is split into 8 elements, flexible connections are made of 20 elements of type "Beam4" (3D elastic Beam with 6 nodal DOF) and wires are elements "Link10" (3 nodal DOF). The resolution of the kinematic process is the same as described in . The principle is to solve the transient equilibrium equation:

$$
[\mathrm{M}]\{\ddot{\mathrm{u}}\}+[\mathrm{C}]\{\dot{\mathrm{u}}\}+[\mathrm{K}]\{\mathrm{u}\}=\{\mathrm{f}\}
$$

Where, $[\mathrm{M}],[\mathrm{C}]$, and $[\mathrm{K}]$ are respectively the matrices of the structural mass, damping and stiffness with $\{\mathrm{u}\},\{\dot{\mathrm{u}}\},\{\ddot{\mathrm{u}}\}$, the nodal displacement, velocity and acceleration vectors; $\{\mathrm{f}\}$ the applied load vector. In our case, $\{\mathrm{f}\}=\{0\}$, and we chose $[\mathrm{C}]=0.01 \times[\mathrm{K}]$ as presented by Morterolle (Morterolle et al. 2015). Equations are solved by the Newmark's time integration method. The convergences criterions are those usually used in the literature in Force, Moment, Rotation, and Displacement. At the first step of the dynamic calculus, the locked nodes are released in rotation and displacement. The predefined length of the wire cables, representing cerclage cables permits to control the aperture of the rim.

The physical and geometrical properties of the elements for this simulation are shown in Tab. 1. Modeling was completed with various numbers of bars for different $\alpha$ angles 
(Table.2). The results are very satisfactory. Indeed, the modeling difference with respect to analytical model defined by Eq.39 and Eq.40 does not exceed $0.87 \%$ for the moment and $0.65 \%$ for the tension in the cable (Tab.2).

Table 1. Modeling of elements

\begin{tabular}{cccccccc}
\hline & \multicolumn{3}{c}{ Geometry } & \multicolumn{3}{c}{ Mechanicals properties } \\
\cline { 2 - 8 } & $\begin{array}{c}\text { Length } \\
(\mathrm{cm})\end{array}$ & $\begin{array}{c}\text { Diameter } \\
(\mathrm{mm})\end{array}$ & $\begin{array}{c}\text { Thickness } \\
(\mathrm{mm})\end{array}$ & $\begin{array}{c}\text { Inertia } \\
\text { moment } \\
\left(\mathrm{m}^{4}\right)\end{array}$ & $\begin{array}{c}\text { Density } \\
\left(\mathrm{kg} / \mathrm{m}^{3}\right)\end{array}$ & $\begin{array}{c}\text { Poisson } \\
\text { ratio }\end{array}$ & $\begin{array}{c}\text { Young } \\
\text { Modulus } \\
\left(\mathrm{N} / \mathrm{m}^{2}\right)\end{array}$ \\
\hline tube (aluminum) & 40 & 6 & 1.5 & $51.05 \mathrm{E}-06$ & 2700 & 0.346 & $70 \mathrm{E}+09$ \\
joint (steel cable) & 2.5 & 3 & - & $0.042 \mathrm{E}-12$ & 7500 & 0.3 & $125 \mathrm{E}+09$ \\
wire (steel cable) & vary & 1 & - & - & 7500 & 0.3 & $125 \mathrm{E}+09$ \\
\hline
\end{tabular}

Table 2. Comparison between analytical and ANSYS® results for different number of bars N and angle of aperture $\alpha$.

\begin{tabular}{ccccccccc}
\hline $\mathbf{N}$ & $\boldsymbol{\alpha}$ & $\mathbf{L}_{\mathbf{w}}(\mathbf{m})$ & $\mathbf{T}(\mathbf{N})$ & $\mathbf{T}^{\text {FEM }}(\mathbf{N})$ & $\boldsymbol{\delta}_{\mathbf{F}}(\boldsymbol{\%})$ & $\mathbf{M}_{\text {Joint }}(\mathbf{N m})$ & $\mathbf{M}_{\text {Joint }}{ }^{\text {FEM }}(\mathbf{N m})$ & $\boldsymbol{\delta}_{\mathbf{M}}(\boldsymbol{\%})$ \\
\hline 4 & $45^{\circ}$ & 0.173 & 2.593 & 2.610 & 0.65 & 0.495 & 0.499 & 0.76 \\
8 & $60^{\circ}$ & 0.221 & 2.466 & 2.477 & 0.43 & 0.440 & 0.444 & 0.87 \\
12 & $90^{\circ}$ & 0.305 & 2.279 & 2.277 & 0.11 & 0.330 & 0.333 & 0.79 \\
16 & $120^{\circ}$ & 0.370 & 2.165 & 2.160 & 0.21 & 0.220 & 0.221 & 0.67 \\
20 & $162^{\circ}$ & 0.420 & 2.098 & 2.092 & 0.30 & 0.066 & 0.066 & 0.19 \\
\hline
\end{tabular}

\section{Modal analyses of the rim}

In order to verify the rigidity of the rim, modal analysis were performed. The rim is made of tubes that are end restraint node by node. The support is modeled by locking displacements and rotations in the middle of one bar.

The rim is made of carbon-epoxy tubes, $1 \mathrm{~m}$ long, for a $3 \mathrm{~cm}$ diameter and a $1.5 \mathrm{~mm}$ thickness. 

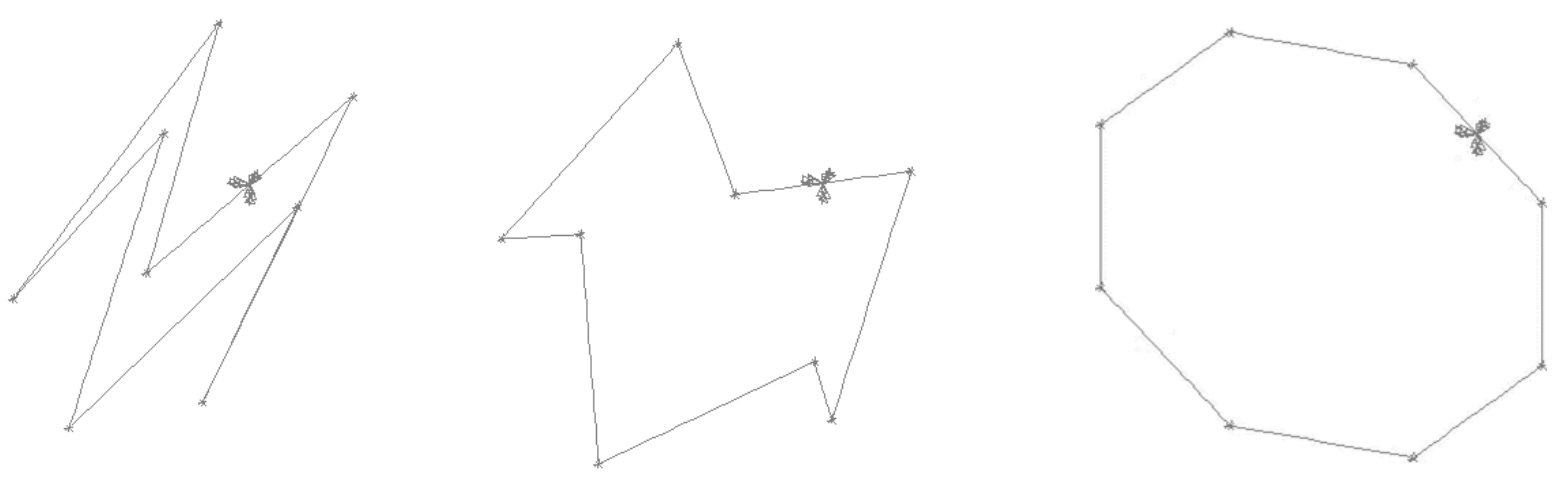

Fig. 23. Rim for different aperture angles

Table 3. Modal analysis results

\begin{tabular}{|c|c|c|c|c|c|c|c|c|c|c|c|}
\hline \multirow[b]{2}{*}{$\mathrm{N}$} & \multirow[b]{2}{*}{ Mass (kg) } & \multirow[b]{2}{*}{$\boldsymbol{\theta}$} & \multicolumn{2}{|c|}{ Stowed } & \multicolumn{6}{|c|}{ Partially open } & \multirow{2}{*}{$\begin{array}{c}\text { Plane } \\
90^{\circ}\end{array}$} \\
\hline & & & $10^{\circ}$ & $20^{\circ}$ & $30^{\circ}$ & $40^{\circ}$ & $50^{\circ}$ & $60^{\circ}$ & $70^{\circ}$ & $80^{\circ}$ & \\
\hline \multirow{2}{*}{6} & \multirow{2}{*}{1.25} & 1st frequency $(\mathrm{Hz})$ & 21.24 & 16.40 & 12.88 & 10.71 & 9.37 & 8.54 & 8.05 & 7.79 & 7.71 \\
\hline & & Rim Diameter (m) & 0.30 & 0.59 & 0.87 & 1.11 & 1.33 & 1.50 & 1.63 & 1.71 & 1.73 \\
\hline \multirow{2}{*}{8} & \multirow{2}{*}{1.67} & 1 st frequency $(\mathrm{Hz})$ & 14.59 & 9.98 & 7.44 & 6.05 & 5.23 & 4.74 & 4.45 & 4.29 & 4.24 \\
\hline & & Rim Diameter (m) & 0.42 & 0.83 & 1.21 & 1.55 & 1.85 & 2.09 & 2.27 & 2.38 & 2.41 \\
\hline \multirow{2}{*}{10} & \multirow{2}{*}{2.08} & 1st frequency $(\mathrm{Hz})$ & 10.50 & 6.63 & 4.81 & 3.87 & 3.33 & 3.01 & 2.82 & 2.72 & 2.69 \\
\hline & & Rim Diameter (m) & 0.53 & 1.05 & 1.54 & 1.98 & 2.36 & 2.67 & 2.89 & 3.03 & 3.08 \\
\hline \multirow{2}{*}{12} & \multirow{2}{*}{2.50} & 1st frequency $(\mathrm{Hz})$ & 7.84 & 4.69 & 3.36 & 2.69 & 2.31 & 2.08 & 1.94 & 1.88 & 1.86 \\
\hline & & Rim Diameter (m) & 0.65 & 1.28 & 1.87 & 2.40 & 2.86 & 3.23 & 3.51 & 3.68 & 3.73 \\
\hline \multirow{2}{*}{20} & \multirow{2}{*}{4.16} & 1 st frequency $(\mathrm{Hz})$ & 3.19 & 1.74 & 1.22 & 0.97 & 0.83 & 0.74 & 0.70 & 0.68 & 0.66 \\
\hline & & Rim Diameter (m) & 1.10 & 2.16 & 3.16 & 4.06 & 4.84 & 5.47 & 5.93 & 6.22 & 6.31 \\
\hline
\end{tabular}

Where $\theta$ is the angle defined by Eq. 42 .

$$
\theta=\operatorname{asin}\left(\frac{\sin \frac{\alpha}{2}}{\cos \frac{\pi}{n}}\right)
$$

As described in Table.3 and in Fig. 24, the first Eigen frequency value decreased in function of $\theta$ and in function of the mass but it is also superior to $1 \mathrm{~Hz}$ for $\mathrm{N} \in \llbracket 6,12 \rrbracket$, that could qualify this rim for space applications. 


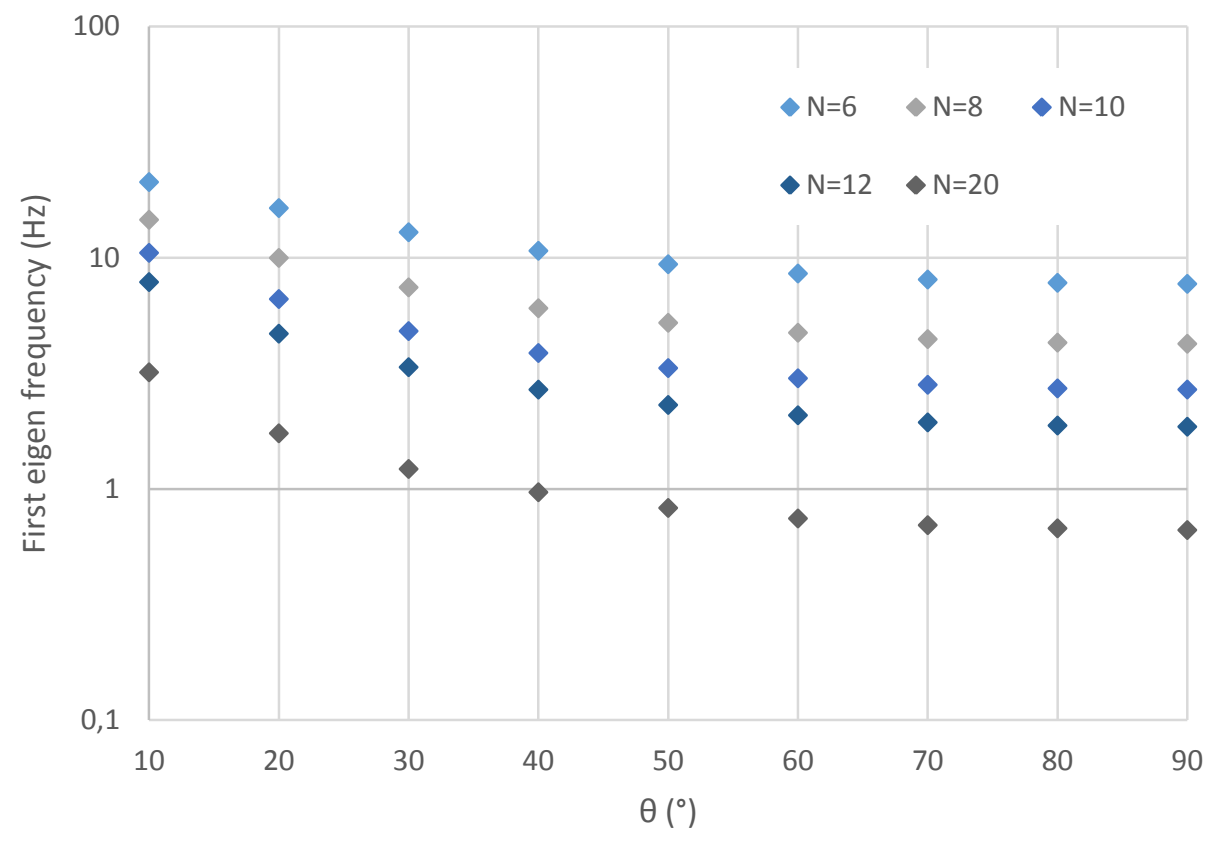

Fig. 24. First Eigen frequency in function of the aperture angle $\theta$

\section{Discussion}

This paper presents a new kind of deployable structure made of bars and flexibles joints. Some models were presented.

The assembly of several modules form an auto-deployable structure (grid) which will be used as support plan of reflectors or solar panels.

A geometrical analysis was done on the module and on the rim. We calculate the optimal surface, volume and the length of the elements exactly. For a flat geometry (full deployment), with a given surface, a length of bar fixed, an equation of the bar number is established. Finally, a static analytical model of the ring is proposed and validated using FEM analyses. Also two packing configurations are presented.

A demonstrator of solar sail was built, with bars in glass fiber, steel compression springs and a $13 \mu \mathrm{m}$ thick Mylar sheet (Fig. 25). It allowed testing the compactness and the folding of a complete set sail structure for a 1-circle configuration. 

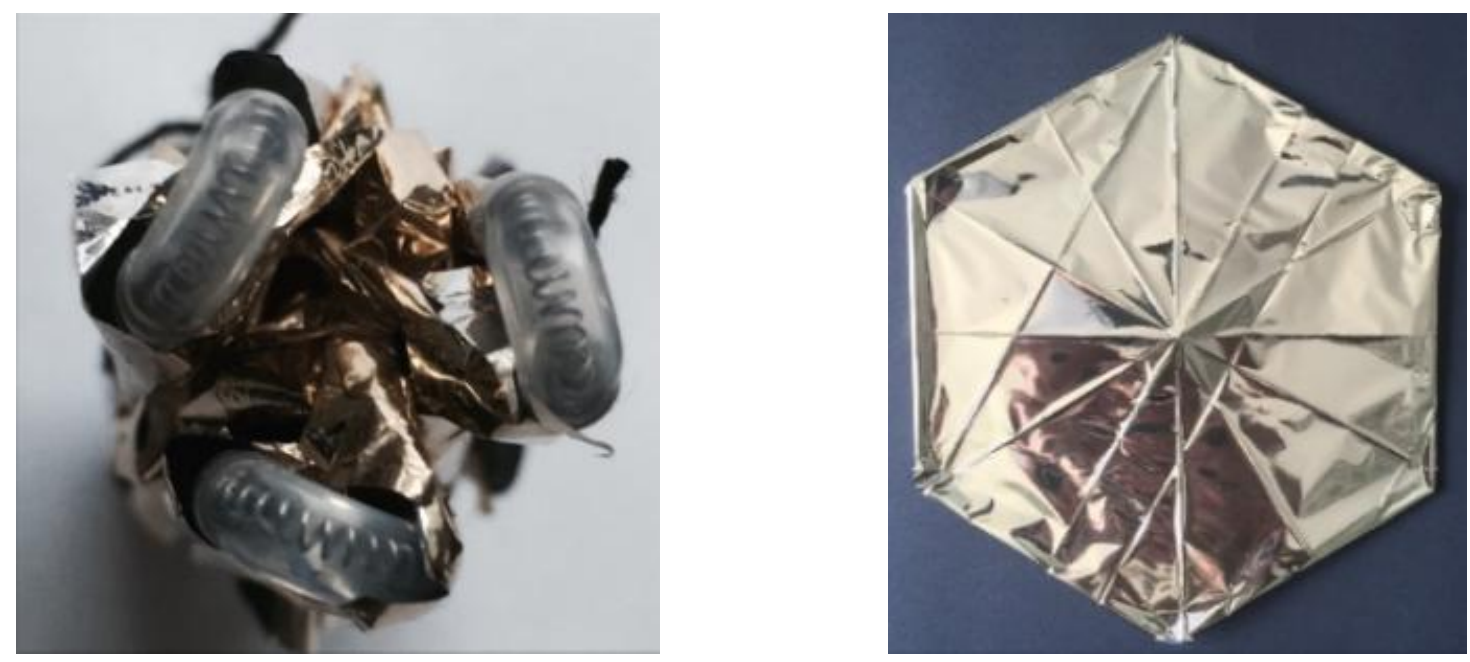

Fig. 25. Physical demonstrator in initial and final step

Another model made up of aluminum tubes and tension springs for connections was elaborated. Bars are $6 \mathrm{~mm}$ diameter with a thickness of $1.5 \mathrm{~mm}$. Springs coming to insert into tubes are $3 \mathrm{~mm}$ diameter, and are arranged so that their length between two bars is $1.4 \mathrm{~cm}$. We represent in Fig. 26 several pictures of our 6 bars partially open structure. A crossing cable passing through the middle of the bars control the spread.
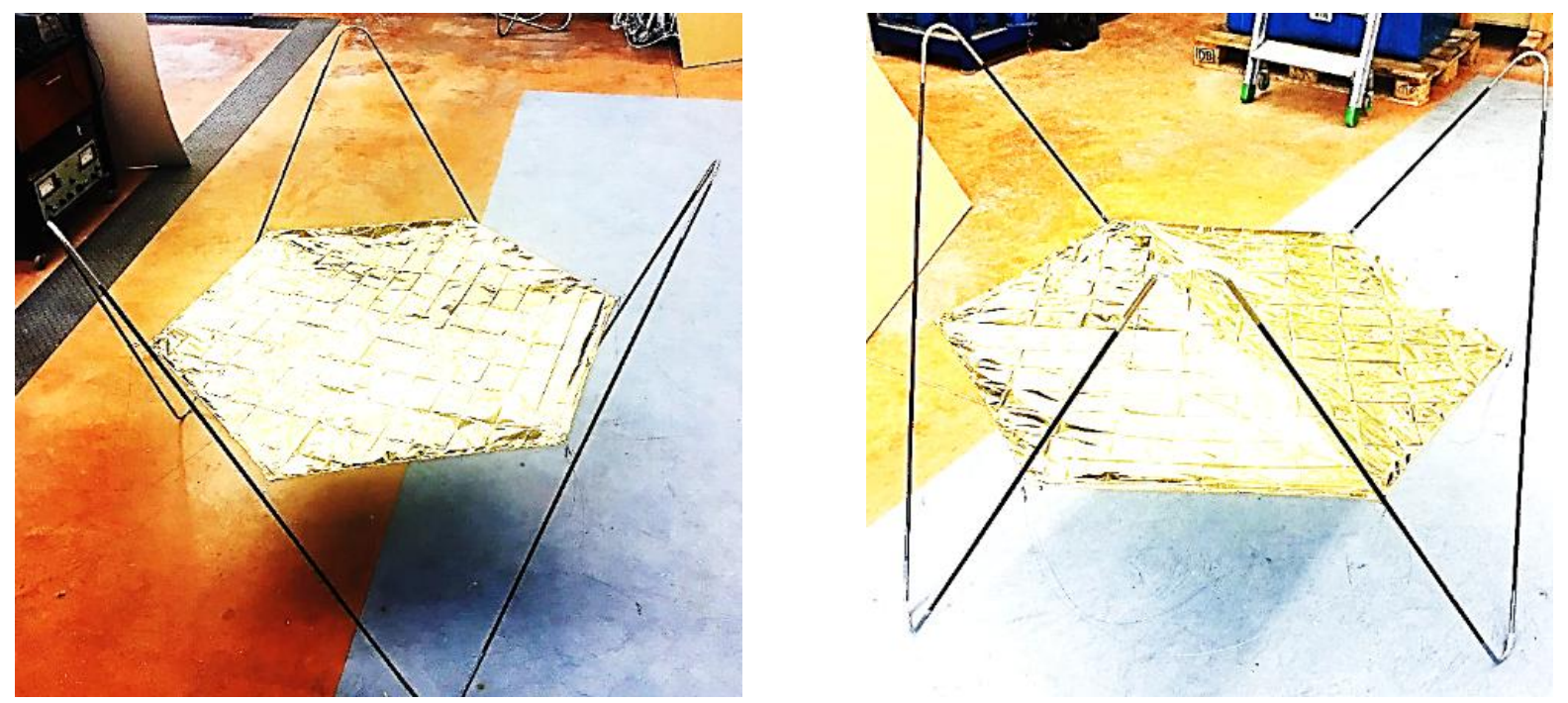

Fig. 26. Physical rim model partially open

Some additional works are currently performed to model the dynamic of the deployment of the structure from stowed configuration to operational phase. By taking into account 
interaction between the structure and the payload (solar sail, antenna...), we will propose a completed solution for space applications. 


\section{Reference}

Chu, Z., Deng, Z., Qi, X., Li, B. (2014). "Modeling and analysis of a large deployable antenna structure.” Acta Astronautica, Vol.95, 51-60.

Fraux, V., Reveles, J. R., Lawton, M. (2014). “Novel Large Deployable Antenna Backing Structure Breadbord Test Campaign.” Proc., The $2^{\text {nd }}$ International Scientific Conf., Advanced Lightweight Structures and Reflector Antennas, Tbilisi, 131-137.

Jianzheng, W., Ruiqiang, M., Huifeng, T., Bo, S., Yufei, L. (2014). "Structure Analysis of Inflatable Solar Sails.” Proc., The $2^{\text {nd }}$ International Scientific Conf., Advanced Lightweight Structures and Reflector Antennas, Tbilisi, 138-145.

Morterolle, S., Maurin, B., Dube, J., Averseng, J., Quirant, J. (2015). "Modal behavior of a new large reflector conceptual design.” Aerospace Science and Technology, Vol. 42, 74-79.

Mouthuy, P.O., Coulombier, M., Pardoen, T., Raskin J.P, \& Jonas A-M. (2012). "Overcurvature describes the buckling and folding of rings from curved origami to foldable." Nature Communications, Vol.3, 1290.

Quirant, J., Cevaer, F., Morterolle, S., Maurin, B., and Dubé, J, (2011). “Conceptual Design and Analysis of a Deployable Structure with Flexible Joints.” J. Aerosp. Eng., 277-284.

Thomson, M.W., (2000).“The astromesh deployable reflector.”. Iutam-Iass Symposium on Deployable Structures: Theory and Applications.” Vol.80, 435-446.

Viquerat, A.D., Guest, S.D., (2013). "Designing Folding Rings Using Polynomial Continuation, Journal of Mechanisms and Robotics.” Vol. 6, No.1, 011005-011016.

Wang, W., Rodrigue, H., Ahn, S.H. (2016). "Deployable Soft Composite Structures.”, Scientific Reports, Vol.6. 
Xu, Y., Guan, F., Chen J., Zheng Y., (2012). "Structural design and static analysis of a double-ring deployable truss for mesh antennas.” Acta Astronautica, Vol.81, 545-554.

Zhang, T., Wu, M., Guan, F., (2016). “Deployment study on a single-layer deployment truss structure driven by elastic component.” IASS Symposium, Vol. 57, No.4, 285-294.

Fig. 1. Self-deployable scissor structure module using flexible joints deployment ............................... 2

Fig. 2. Deployment of a structure made of scissors with flexible joints (LMGC) .................................... 3

Fig. 3. Initial and last step ( $\omega$ fixed) of the deployment of a basic tetrahedron module.......................... 3

Fig. 4. Basic module - Phases of deployment, stowed, volumic and flat configurations ....................... 4

Fig. 5. Geometrical parameters in the stowed $(\alpha=0)$ and partially open configurations...................... 5

Fig. 6. Different approaches to determine the volume of a module. .................................................. 6

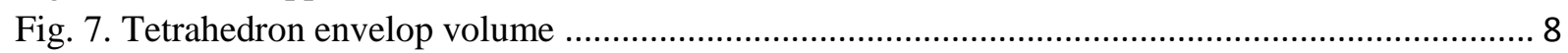

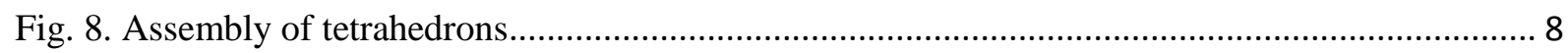

Fig. 9. Progressive steps in the deployment of an assembly of 4 modules ......................................... 9

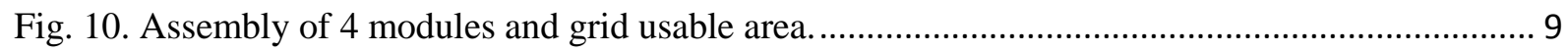

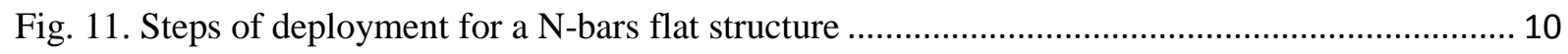

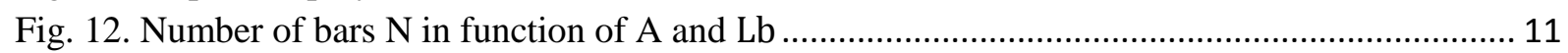

Fig. 13. Schema for a "one circle" configuration (a) "two circles" configuration (b) .......................... 12

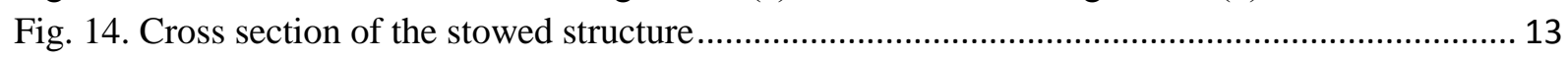

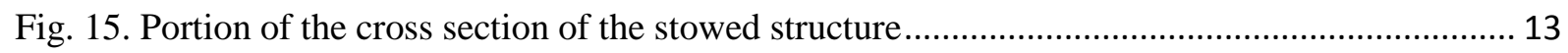

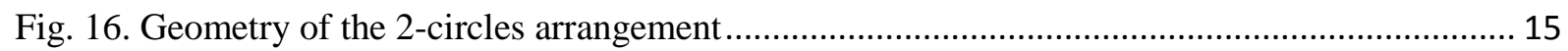

Fig. 17. Ratio of the radiuses of 2-circle configuration by 1-circles configuration in function of $\mathrm{N}$.... 15

Fig. 18. Comparison between the maximum radiuses of the bars for the two configurations with

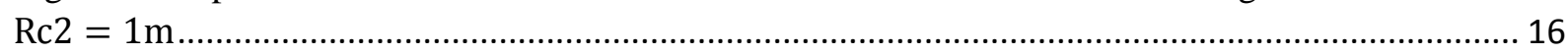

Fig. 19. Two stage of deployment of the ring for a 2 circle configuration....................................... 17

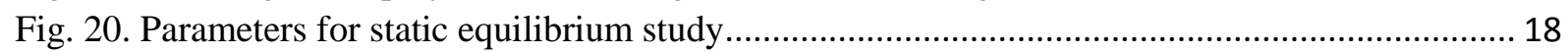

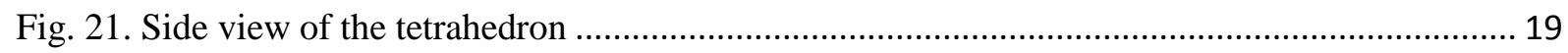

Fig. 22. Tension in wires and bending moment in joints for a given configuration............................ 21

Fig. 23. Rim for different aperture angles ................................................................................ 24

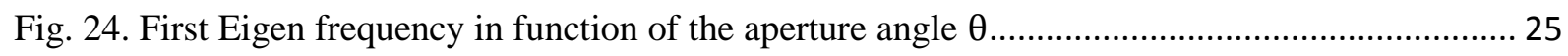

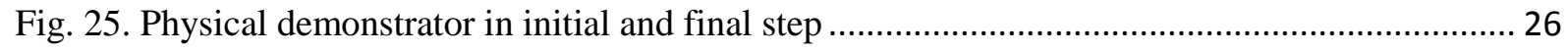

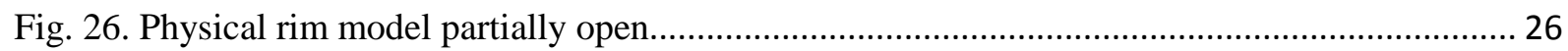

Table 1. Modeling of elements

Table 2. Comparison between analytical and ANSYS $®$ results

Table 3. . Modal analysis result 